flexion of the fingers or wrist is in the direction of extension of the elbow, and the biceps contracts so as to prevent the elbow being extended when the pressure on the wrist or fingers reaches a certain amount. But when the forearm is in the pronated pusition the conditions are reversed, the direction of the opposition to the flexion of the wrist is now in the direction of flexion of the elbow, and to prevent the elbow being flexed it is now the triceps which contracts and not the biceps.

To elucidate still further the question of position I have made experiments on the movement of grasping with the tingers and thumb, $(a)$ with the forearm resting free on a flat suriace, (b) with the forearm fixed immovably. It will be seen on looking at the table that in the movement of grasping the contraction of the triceps occurs sooner than that of the biceps. As there was evidently some disturbance of the position of the elbow which necessitated contraction of the triceps before that of the biceps, the forearm was fixed to prevent any movement of the elbow. It was found that in the position of supination. whereas with the forearm resting freely, the triceps contracted when the grasp registered $24 \mathrm{lb}$.; with the forearm fixed, it did not contract till the grasp was almost doubled, that is, $45 \mathrm{lb}$. In the position of pronation with the forearm free the triceps contracted when the grasp was $13 \mathrm{lb}$., and with the forearm fixed at $29 \mathrm{lb}$. The same conditions were obtained when the forearm was in the mid-position between supination and pronation. The contraction of the biceps was not influenced by the position of the forearm being free or fixed, Tnese observations showed that the contraction of the triceps must be to counteract some action of flexion of the elbow by the muscles taking part in grasping, and on carefully watching the movement of grasping when the forearm rested free on a flat surface, a certain degree of flexion of the elbow was seen. I have measured the force of this flexion of the elbow by a band round the lower end of the forearm, which was attached to a fixed point with a spring balance interposed, and $I$ find that the force exerted by the flexion of the elbow in grasping amounts to I lb. I have also ascertained that it makes no difference whether the grasp is $24 \mathrm{lb}$. or the maximum $54 \mathrm{lb}$., as the amount of force produced by this slight flexion of the elbow is in both cases I lb. This would mean that in the supinated position whatever the strength of the grasp, the triceps so adapts itself that it will not permit flexion of the elbow of more strength than $\mathrm{I} \mathrm{lb}$.

Another question which arises is, Why in the supinated position does the triceps not co-operate till the grasp has reached $24 \mathrm{lb}$., whereas in the pronated position it takes part in the movement when the grasp has reached $13 \mathrm{lb}$., and in the mid.position at $20 \mathrm{lb}$. between the two other figures? It means probably that in the position of pronation the forearm muscles produce flexion of the elbow sooner than in the position of supination, and, therefore, that the triceps must intervene sooner to prevent flexion of the elbow. If this be true it is in harmony with what was stated in a previous lecture-that patients who have lost their proper flexors of the elbow manage to flex this joint by first putting the forearm into the position of pronation and using their forearm muscles.

REFERENCES.

1 The Anatomical Exposition of the Structure of the Human Body, Fourth Edition. 9 III, pp. $320,372 .{ }^{2}$ Loc. cit., p. 249. ${ }^{3}$ Arch. de Physiol. Fifth Series. Tome i. 1889. 4 Ibid.. Fifth Series. Tome ii. 1890. 5 Proc. Roy Soc. vol. liii, p. 407. ${ }^{6}$ Proc. Roy. Soc. 1897. vol. 1xii. ${ }^{7}$ Brain, vol. xiv. r8gr. 8 BRITISH MEDical JouRNAL, October ist, 1898. 9 Brain, vol. xiv. 189r. 10 Physiologie Artistique. 11 Brain, vol. xiv, p. 57. r89r. 12 F. Gotch, 189r. 10 Physiologie Artistique. 11 Brain, vol. Xiv, p. 57. 189r. 12 F. Gotch,
Jour. of Phys., December 15th, 1902. 13 Phil. Trans. Series B. vol. cxc. 1898, p. 154 .

\section{THE ETIOLOGY OF NEW GROWTHS.}

\section{By KEITH W. MONSARRAT, M.B., F.R.C.S.EdIN.} Surgeon to the Northern Hospital, Liverpool.

Althovgh it is not unusual to speak of the coll growth of benign tumours as typical and that of malignant tumours as atypical, such terms are applied to cell relationships and not to cell types. That new growths are composed of aberrant cells, often markedly different morphologically from those of the organ of origin, is long recognized; from the physiological side, also, it has been shown that the vegetative properties of such cells are developed at the expense of the specialized functions of those of the organ of origin. So far is this altera- tion in type recognized that many pathologists have assumed a reversion to an "embryonic" state as an essential in all tumour growth. The use of the term embryonic has been with reason condemned by Adami ; if the term is used in any strict sense it is inaccurate; the cells of many new growths have no demonstrable morphologica! resemblances to embryonic types, and physiologically their one resemblance is the preponderance of the vegetative properties.

It appears to be correct to state that all tumour growth is error, typically speaking; it is the purpose of this paper to examine this type variation and its significance.

Cell Activity.

All cellular activity is the resultant of bio-chemical action and reaction, and, did our knowledge admit, all cell phenomena would be definable in terms of this action and reaction from a comparatively simple phenomenon, such as that of secretion, to the infinitely elaborate processes which result in the evolution of the body and its parts from a simple cell. During this evolution, cell types are continuously built up of wide morphological differences and performing ultimately widely different functions.

Such characteristic cell types maintain themselves in virtue of an inherent selective activity on the assimilable material available to them, enabling them to build uo characteristic chemical compounds.

Cell potentiality may be stated conversely-all cells react to bio-chemical stimulation, and the result depends on two factors, the nature of the stimulus and the inherent capabilities of the cell to form chemical combinations in response. By the term stimulus is to be understcod any incidental condition which calls forth chemical change of whatever character in the cell. The secretory cell of a salivary gland depends for the porformance of its characteristic functions on the availability of suitable assimilable material, and also, at any rate as regards its degree of activity, on impulses transmitted through the nervous system-an example of the transformation of energy.

The discoveries of Professor Ehrlich in his investigation of immunity have thrown much valuable light on the question of cell activity generally. It is perhaps too early to generalize on this matter, but it may be provisionally stated that the selective power of a specific cell type in presence of the available food material, depends on its possession of "receptor" groups corresponding to "haptophore" groups in the assimilable material, and the production as a chemical reaction of molecular combinations which may be used up in cell maintenance, or under other circumstances, and in the case of other cell types, in the formation of a secretion of approximately constant character. A consequence of the reaction of receptor and haptophore groups is the reproduction of receptors, and this saturation and reproduction would appear to exercise an influence of first importance on the variations of cell activity and their cyclical regulation.

\section{Cell Proliferation.}

The response of cells to "stimulation" is frequently expressed as reproduction. A great variety of forms of stimulation, using the term in the sense already defined are capable of initiating this reproduction; alteration of chemical conditions such as those evoked by heat and moisture are well recognized methods of encouraging multiplication among the simpler form of animal and vegetable life, and among these forms the influence of a variety of organic and inorganic salts on this multiplication has been the subject of researches.

The same class of conditions also governs multiplication of the tissue cells of the human body-examples of such conditions are to be found in (I) increase of available food material of normal type, (2) the alteration of physico-chemical conditions which is brought about by mechanical irritation, and (3) the activity of certain microparasites and their products. Almost all cells of the body are capable of multiplying in response to such stimuli, the probable exceptions are the more highly specialized cells of the nervous system, and possibly others similarly specialized; others in varying degree appear to retain a vegetative function.

This vegetative function is part of the normal life-cycle of the parenchyma of the ovary and testis; in other tissues it is, for the most part, potential ; in this function, as in all cell activity, the nucleus appears to exercise a controlling influence, and its changes are readily demonstrable histologically.

First, $a$ word on the most simple of the three conditions named above-proliferation as the result of increased, or 
inereased availability of food material. The stimulus here is the normal food material. Under ordinary circumstances this is attached to the cell by specific affinities or receptors, and utilized in the chemical changes which are peculiar to the cells concerned. Muscle cells will serve as an example. Under the exceptional circumstances of increased supply the cell goes beyond the performance of its normal function, and the nucleus, which is an index of all cell changes, divides as a whole. New muscle fibres are formed, in part at any rate, by, first, a multiplication of nuclei ; and, secondly, a separation off of a new individual cell body corresponding to each. We are not aware of the necessity of any constituent change in the food supply stimulus neceseary to evoke this vegetative function; possibly there is some change in molecular tension; but that it is increased supply, and not constituent change, which is responsible, is, I think, supported by the result - that result being the production of a cell similar in type to the parent cell in all ascertainable respects.

It is necessary to expluin this last argument further. If we are to consider the vegetative function one dependent on chemical conditions, we must assume that it obeys such chemical laws as are universally followed in other chemical reactions. It has long been the custom to speak of this vegetative function as physiological, suggesting that it belongs to the class of so-called vital functions, to the interpretation of which we are supposed to possess but scanty clues. The burden of proof now lies with those who suggest or maintain that this so-called vital process has any basis other than a chemical one. The differences of opinion on cell processes generally are well illustrated by the recent discussions on the reactions of toxin, cell, and antitoxin; the present consensus of opinion is also shown by the almost universal acceptation of Ehrlich's view that these reactions depend on chemical affinities and not on come physiological reaction distinct from chemical combination, which was the view put forward by Büchner, Wassermann, and others.

If, then, we are dealing with a bio-chemical problem in this question of muscle-cell multiplication, the result, which is the production of a cell of a type exactly resembling the parent, throws some light on the character of the process; it supports the view that the real effective cause of the multiplication in this case is an increase in available quantity or assimilability of the normal food supply, the normal assimilable material. If it depended upon some change in this assimilable material, and consequently upon new chemical reactions, we should expect not a daughter cell of type exactly resembling the parent cell, but a daughter cell of type variant to a greater or less degree.

We are not able with our present knowledge to go deeply into this matter, but I think the following corollary may be stated with probable accuracy-in regard to the vegetative function of cells, when this is evoked by an increase in quantity or assimilability of the normal assimilable material, the daughter cell is similar in type to the parent cell.

I do not propose to dwell on proliferation dependent " on the alteration of the physico-chemical conditions which is brought about by mechanical irritation," but to pass to consider that which results from the activity of certain microparasites and their products.

Proliferation in Micro-parasitic Infhctions.

Proliferation of this type takes place in response to the action of assimilable material, which is usually called toxic owing to one aspect of the result of its activity. An example is the proliferation of the fixed connective-tissue corpuscles, which results in certain cases from the action of the tubercle bacillus-any of the so.called inflammatory processes would serve, but it is well known that the extent to which proliferation is evoked by the different infective agents varies greatly.

We may express the effect of the tubercle bacillus and its products on the connective-tissue corpuseles in the following way :

Assimilable Stimulant, (Haptophore Group-Receptor Group ) Connective that is,

ubercle Bacillus, $\{$ Germinal Group-Germinal Group $\}$ Corpuscles

and products $=$ Proliferation of connective-tissue corpuscles

Now of course this only represents one aspect of the action of the bacillus, other aspects are the death of the corpuscles or possibly their stimulation to the production of antitoxin, though the source of antitoxin bodies is uncertain; in these varions effects, common receptor and haptophore groups are very probably concerned. However that may be, numbers of new cells are produced related by descent to the connectivetissue corpuscles. They are not the result of increased supply of normal assimilable material, but of assimilable material of foreign and abnormal character. We should expect therefore that while showing resemblances to the connective-tissue corpuscle they would show variations in type, in fact if the view of cell proliferation as a bio-chemical reaction is correct this variation must apparently follow. Morphologically the new cells show evidence of this variation, associated presumably with alteration in their constitution. From this evidence and for these reasons we are justified in stating that the result of the action of this micro-parasitic infection is the production by proliferation of cells of a type variant from the normal type and therefore possessing new bio-chemical characteristics and affinities.

These new cells thus produced are in a state of unstable equilibrium, which is shown usually by their death in large numbers, and their disappearance during processes of healing. This disappearance has an active and passive aspect. On the one hand, they die as a result of the toxic or over-stimulating action of the parasite and its products ; on the other hand, being dependent for their maintenance on chemical conditions of a temporary character, if these latter disappear, the new type will fail to maintain itself, degenerate, and be absorbed, or will revert to the normal type under the influence of the normal assimilable material, which, after neutralization of the infective agent, becomes the only food available.

The extent to which this reproduction reaction to stimulatakes place varies very much-the factors being, first, the nature and persistence of supply of the assimilable stimulus, second, the specific receptor activity of the cells with which this is brought in contact.

In the case oi the so-called toxin bodies, their selective activity on certain tissues and cells is well known-for example, the tetanus toxin, which acts selectively on the cells of the central nervous eystem. In the same way, certain microparasites exert this reproduction reaction specificallyfor example, the coccidium oviforme excites proliferation of the epithelial cells of the bile ducts, the infective agent of syphilis excites proliferation of the connective-tissue cells.

\section{Granulomata.}

In the case of some contagious disorders there result what are spoken of as granulomata. These consist of cells produced as a reaction to the stimulus of an invading agent; cells of such a type and with such relations to the assimilable stimulus that they are comparatively persistent-for example, gummata. But, however active the proliferation, the cell type of the gumma is unstable; the factors above referred to lead either to death or to reversion. The influence of potassium iodide on this cell growth is of interest; its action is probably one of neutralization of the assimilable material which is able to originate proliferation, and owing to the availability of which the new cell type is able to maintain itself for a time.

The gumma is a new growth arising from the basis of the connective-tissue corpuscles; venereal disease also supplies us with an example of a new growth originating as epithelial proliferation-the condyloma.

It is interesting to note statements that these condylomata are not true tumours; for example, in a textbook on pathology, the first edition of which is not two years old, I read of this growth "being due to irritation, it is not in a strict sense a tumour." The meaning of this is, of course, that being definitely etiologically related to certain forms of irritation, it cannot be called a true tumour, because part of the definition of Itrue tumours is that they arise without assignable cause. Such argument is based on the dogma that there is no such thing as a formative irritant; a dogma energetically preached by Weigert and others, but which seems to require modification.

To leave this point; the condyloma acuminatum is a new growth which is histologically a papilloma; it arises as a consequence of the stimulation of the skin by certain contagious infective agents. From the cells of the rete are produced by this reaction cells of a variant type which continue to multiply and also maintain themselves indefinitely.

Such an example serves to enable us to make the following statement: As a result of the action of external and communicable stimulants there result, by proliferation, new growths of cells of variant type, the persistence of which is variable, in some cases transient, in others indefinite.

Cell Trpes of the So-called True Tumours.

We have considered the question of the decadence of the new cell type and the agencies, active and passive, by which 
it is brought about-we now have to consider the persistence of the variant cell type.

This may be discussed in relation to one of the benign new growths, for example the adenoma.

In the very valuable paper by Professor Adami, in the British Medical Journal of March 16th, 1901, the author states his view that cell proliferation occurs

where the tensions acting on the cell are reduced and certain energies, which before were necessary to counteract opposing forces, are freed and become thus capable of diversion from their purpose, or again where stimulation from without results in increased assimilation - he considers that "owing to these agencies the proliferated cells assume a "habit of growth' as contrasted with a ' habit of work' (for example, the performance of their normal funetions) and acquire momentum to continue performing the proliferstive act.

When this habit of growth is inaugurated the cells can continue to grow and multiply in the completel absence of those conditions which initiated their proliferation in the first place.

The last part of this quotation is that with which $I$ am really concerned. How is it that the proliferated cells can continue to grow and multiply indefinitely? Professor Adami considers this explainable on the ground of momentum.

This explanation does not, I think, take sufficiently into consideration the resistance to which these cells are subjected at every stage of their life-history; from beginning to end they have to maintain themselves in the face of reactionary forces. Granted their habit of growth-but why do they survive and as it were become colonists and settlers, seeing that they are outlanders and foreigners ?

It seems to me that we must look to the question of cell type for an explanation, this question being one of chemical characteristics and affinities, and we may go again to bacteriology for an illustration. A certain type of bacillus may be possessed of a habit of growth of high degree, but it will obtain no footing whatever in the human body unless it is possessed of such chemical affinities as enable it to attach itself to elements of the material of the body, and so to maintain itself and survive reactionary and lethal forces. This survival is a question of bacterial type, and only secondarily one of proliferative energy.

Valuable supporting evidence of this view is also afforded by transplantation experiments, of which I will take those of Jensen and Leyden. Jensen ${ }^{1}$ was able to transplant a cystic adeno-carcinoma and a melano-sarcoma of the mouse through a long series of animals of the same species; attempts to transplant into other animals were uniformly unsuccessful. V. Leyden ${ }^{2}$ transplanted a sarcomatous growth through forty-eight generations of white rats; but in white mice, guinea pigs, and rabbits no growth resulted. In these experiments we have examples of the habit of growth of a high degree, but while the cell type was able to maintain itself in the species of origin, this was impossible in other species, because of its inability to form such bio chemical relationships in the new species as would enable it to survive and vegetate.

From these examples I turn again to the question why certain types of abnormal proliferate cells persist, survive, and multiply indefinitely, and the answer seems to be that they are initially possessed of certain affinities which are able to attach themselves to certain corresponding elements of the available assimilable material, and in consequence maintain their equilibrium. The matter resolves itself into a question of immunity.

To discuss fully how this stable, this immune cell type is or may be evoked would entail consideration of the various etiological theories; I shall content mgself with repeating that variant cell types can only be called into existence by alterations in chemical conditions, and we may speak of the abnormal materials as stimuli or as new assimilable materials with characteristic affinities: the se are synonymous terms. I think it probable that there exist a variety of such stimuli capable of generating stable variant cell types and thus originating new growths; that among these certain microparagites have a place is at any rate a reasonable theory.

With regard to the different cell characteristics of simple and $m$ alignant gcowths, it is becoming increasingly evident that all degrees of malignant and benign growths exist and that the demarcation between the groups has a rather shadowy existence. I will take as examples the three types: adenoma, rodent ulcer, and carcinoma.

I have already said that the conditions of life of the cells of growths are really studies in immunity.

The cell type of the adenoma is stable, but only locally, in the organ of origin, it shows no capacity for extending or maintaining itself outside the range of certain restricted relationships, only within the range of these relationships is it immune to influences which would overturn its equilibrium, for chemical conditions outside these relationships it possesses a negative chemotaxis, or at any rate an indifference.

Rodent ulcer is clinically and pathologically a well-defined type of new growth; it differs from the adenoma in that the cells have a wider range of possible relationships; they transgress the normal relationships of epithelium and connective tissue, and invade the latter. This power of invasion is, however, limited; the growth is always comparatively superficial, and does not extend to the deeper lymphatic channels and glands. The cell type is, then, one which is stable, but with chemical affinities, capable of satisfaction only within a range histologically definable; on the other hand, in virtue of these affinities the type exhibits a positive chemotaxis for conditions other than those of its original seat, and in virtue of this it invades or, as we say, infiltrates. It is usual to speak of this infiltration as governed only by conditions of mechanical resistance; it seems probable that, at any rate, its direction and limitations are defined by this principle of chemotaxis, which, again, is dependent on the chemical affinities of the cell type.

If we in the third place consider a carcinoma of a high degree of malignancy, we find we have to do with a cell type capable of maintaining itself under a great variety of conditions ; for example, a carcinoma mammae with metastases in liver, lungs, bones, and brain. Even in such growths we find limitations and preferences. For example, observations have shown that certain organs are more commonly the seat of secondary growths irrespective of their anatomical relation to the primary focus. Although metastatic cells from a carcinoma mammae must necessarily pass through the lungs before reaching the liver and many be arrested there, yet secondary grow ths are more common in the latter than in the former.

The two chief factors in malignancy, infiltration and metastasis, are then dependent on the extent of the range of stability and immunity of the variant cell type originally evoked. Infiltration is a question of positive chemotaxis. Metastasis is in the first instance governed by mechanical conditions, but in regard to its extension and development is dependent on the power of the cell type to maintain its integrity, resist reactionary influences and utilize material as nutriment under varying bio chemical conditions.

I may now attempt to summarize the various points of this paper.

1. Cell activity and cell type must always be the resultant of bio-chemical reaction of the principles of which the researches of Ehrlich and others have enabled us to obtain some information.

2. Cell proliferation as a form of cellular activity is alwayg the resultant of such reaction. When it takes place as the result of increased availability of normal food material, the new cells produced conform to the type of the parent cells. When it follows the action of assimilable materials of abnormal constitution new cell types are evoked, variants on the type of the parent cells.

3. Cell proliferation of the latter type takes place in certain microparasitic infections.

4. The new cell types thus evoked exhibit various degrees of instability.

5. In the granulomata (Infectionsgeschwïlste) their stability is considerable; in certain growths which result from infective agents (for example, condyloma) the equilibrium of the new type appears to be stable.

6. In the so-called true tumours, cell types arise as variants on the normal cells of the organ or tissue of origin. The ways in which such cell variants may be evoked is not discussed, but that they may result in some cases from the action of micro-parasites is a reasonable view.

7. These cell types are stable; their stability is due to the capacity of the particular variant to attach to itself and assimilate material in conformity with its type.

8. In the simple tumours they are only locally stable, and are not immune to reactionary influences outside the tissue of origin and the normal relationships of parenchyma and connective tissue.

9. In the malignant growths they possess a wide range of stability and immunity, and the degree of this is the measure of their capacity to form metastases, while local infiltration, the other histological characteristic, is dependent on the principle of chemotaxis, the cells extending in those 
directions in which their variant and aberrant bio-chemical affinities enable them to annex material conformable to the building up of their characteristic type.

REFERENCES.

1 Nogle Forsog Med Kraeftsvulster, Copenhagen, sgoz. ${ }^{2}$ Deut. med. Woch., September 4 th, igo2.

\section{A CRITICISM OF CURRENT DOCTRINES CONCERNING HERNIA.*}

BY EDWARD DEANESLY, M.D., B.Sc.LOND., F.R.C.S.ENG.,

Honorary Surgeon, Wolverhamrton General Hospital.

ALTHOdGH hernia is one of the commonest of surgical diseases and the subject of an abundant literature, both ancient and recent, surgeons have by no means attained to anything like unanimity either with regard to its pathology or its treatment. The root of this diversity is the want of a generally accepted theory of causation. Indeed, there exists in most textbooks, and in the minds of many surgeons, what I believe to be a fundamental misconception on this subject, which I shall attempt to show is responsible for much confusion in treatment. Stated briefly, this misconception consists in the belief that the majority of inguinal hernias are acquired, whereas there are, I think, conclusive reasons for believing that all, or almost all, are congenital. The pouch of peritoneum which passes $d(w n$ the inguinal canal into the serotum and forms the peritoneal investment of the testicle and the tunica vaginalis, under normal circumstances becomes completely obliterated between the tunica vaginalis and the internal abdominal ring, within a short but not accurately-known period after birth. In a person in whom this piece of development has been completed in normal fashion, un inguinal hernia can only arise by the protrusion through the inguinal canal of an entirely new sac of peritoneum carried in front of the intestine or other organ which happens to protrude. Such a condition would be a true acquired in. guinal hernia and would be explicable on exactly the same principle as the post-operative hernias. That is to say. it would be the effect of normal or excessive expiratory effort acting on a weak or undefended part of the abdominal wall. This is exactly the view which is commonly held. On a priori grounds there is no objection to this view. There is no greater difficulty in believing that abdominal strain may force gut and peritoneum through the inguinal canal than in believing it capable of causing a hernial protrusion in an abdominal scar. Nevertheless the evidence against inguinal hernia at any rate of the ordinary oblique variety being ever really acquired in this way, independently of any developmental defect is, I think, quite conclusive. The crux of the question is this: does oblique inguinal hernia ever arise without a pre-existing sac formed by a patent or partially patent funicular process?

There is absolutely no reason to suppose it does, and many reasons against such a supposition. In the first place, it is known that inguinal hernia does sometimes arise from a patent funicular process, because in one form the protruded viscera actually lie in the tunica vaginalis, and this form has always been named the congenital variety. But if this occurs when the whole peritoneal pouch remains open, surely it will occur just as readily when only the upper part remains open, and the condition then is anatomically precisely what is found in the ordinary oblique inguinal hernia. But there are many other arguments in support of this view besides its inherent probability. In every oblique inguinal hernia, if examined soon after its appearance, there is a well-marked neck; the aperture of exit is \&mall in relation to the size of the whole sac, which has the shape of a sausage or a pear. In traumatic hernias, on the cther hand, the aperture of exit is relatively large, and the whole hernia has a roughly hemispherical form. Moreover, many inguinal hernias of considerable size appear quite suddenly ; in other words. the sac is already there to receive the protruded viscus. If it were not so, it is almost inconceivable that a pear-shaped pouch of peritoneum several inches in length, and of still greater circumference, could be suddenly extruded from the belly by a single expiratory effort. Any attempt to produce such a condition artificially on the cadaver would certainly rupture the peritoneum.

* Kead betore the Birminguam ana Midland Counties Branch of the British Medical Association.
Again, a hernia may be of congenital origin, namely, due to a pre-existing patent funicular process, and yet not appear at birth or even in infancy. The admittedly congenital variety in which the viscera lie in the tunica vaginalis may make its first appearance at any age. In other words, a patent funicular process may exist for an indefinite number of years without giving rise to hernia, until some extra violent effort, or some weakening of the sphincter muscles of the inguinal canal, forces or permitsthe descent of a portion of the viscera into the sac. If therefore the first appearance of the hernia, that is, the first descent of the viscus into the sac, may be delayed for years in a person in whom the tunica vaginalis communicates freely with the peritoneal cavity, there is no difficulty in believing that a patent funicular process exists from birth in every oblique inguinal hernia, whatever the age at which the bernia first appears. This supposition, moreover, is not a mere hypothesis. The existence of a patent funicular process in patients with no hernia has been several times actually demonstrated as in a case quoted, as by Mr. Langton in his Bradshaw Lecture on the Association of Hernia with Descent of the Testis. I have myself made a similar observation in two cases; one in which an operation for radical cure was accidentally performed on the wrong side, where a patent eac was nevertheless found; another in a case of encysted hydrocele of the cord where the funicular process above the cyst was found widely patent, although previous to the operation there was no hernial impulse or swelling.

Again, Sachs, quoted by Stiles, states that he found the funicular process completely or partly open in 59 per cent. of male children under four months old--obviously a much larger proportion than those possessing hernias at that age.

Lastly, if ordinary oblique inguinal hernia were in some cases due to a pre-existing congenital sac and in others due to the formation of an entirely new protrusion of peritoneum, we should expect to find that the majority of hernias in young children were hernias into the tunica vaginalis, that is "congenital" according to the present nomenclature of the textbooks. As a matter of fact this is not the case. The great majority of the inguinal hernias of young children are precisely like the majority of adult cases, that is the sac of the hernia is completely shut off from the tunica vaginalis. With regard to this point all who have operated on many young children are unanimous, and my own observations, which are numerous, entirely confirm it. The evidence therefore appears to me to establish conclusively the presumption that in all oblique inguinal hernias there is a pre-existing sac formed by a congenital patency of the whole or of the upper portion of the processes vaginalis. That the sac of any oblique inguinal hernia is ever formed by an independent protrusion of peritoneum unconnected with the processus vaginalis there is on the contrary no evidence whatever; indeed the only proof possible would be the demonstration of the coexistence of an unclosed processus vaginalis with a separate hernial sac alongside it. This, so far as I know, has never been observed. It will be noted that the above arguments apply exclusively to the ordinary oblique inguinal hernia which enters the internal ring outside the epigastric artery and traverses the whole length of the inguinal canal; which has in fact the exact anatomical relations of the processus vaginalis. It is obvious that the direct inguinal hernia which leave 6 the abdomen on the median side of the epigastric artery and emerges directly at the internal ring is not explicable in the same manner. It must, I think, be attributed to the same causes as post-operative ventral hernia, that is, it is a genuine newly-formed protrusion of peritoneum and viscera through a naturally weak spot in the abdominal wall. With regard to this hernis the most important point is that it is uncommon. In 120 operations I have met with only two. Like all hernias due primarily to strain the sac is short and wide and never passes far into the scrotum.

The view that many inguinal hernias, beside those into the tunica vaginalis are really congenital in origin is not of course new. Many surgical writers have recognized it. But the merit of first clearly enunciating the view that in practically every inguinal hernia the sac is a pre-existing vestigial structure, and the chief factor in its etiology rests with Mr. R. Hamilton Russel, of Melbourne, whose paper on "The Etiology and Treatment of Hernia in the Young," published in 1899, has not, I think, attracted as much attention as it deserves. It was, however, alluded to and endorsed by Mr. Harold Stiles in his paper on "The Radical Cure of Hernia in Children," read at the annual meeting of the British Medical Association last year. ${ }^{2}$ 